\title{
CONSCIÊNCIA E PERSPECTIVA FEMININA NOS LAIS DE MARIA DE FRANÇA
}

Gabriela Carlos Luz

Resumo: Maria de França foi uma poetisa medieval que escreveu em Francês Antigo no século XII. Sua obra mais conhecida, Lais, é uma recontagem de diversas histórias folclóricas orais conhecidas na época. As personagens femininas destes lais, no entanto, são apresentadas como mulheres com clara consciência de sua perspectiva feminina frente às adversidades da sociedade feudal. Lendo os Lais com uma visão feminina (e em certos casos feminista) podemos ver como a autora criticou ativamente o modelo da ordem social em sua época e como suas críticas condizem com o abuso das mulheres em seu século. Partindo primeiramente de cenas nos lais de "Guigemar", "Yonec", "Equitan" e "Milun" discutiremos como a autora criticou a sociedade machista na qual estava inserida. Demonstraremos também como suas palavras nos mostram um tom de condenação a uma sociedade que ditava que a mulher deveria ser inteiramente submissa a seus parentes masculinos e a seu marido. Utilizaremos os estudos de Georges Duby nos quais ele versou sobre o papel da mulher na sociedade conjugal da Idade Média para ilustrar a perspectiva feminina medieval que a autora expôs, além de vários outros autores e historiadores que estudaram a obra de Maria de França com a consciência do feminino em sua escrita. Palavras-chave: Feminismo. Literatura Medieval. Literatura Francesa. Maria de França

Abstract: Marie de France was a medieval poetess who wrote in Old French in the 12th century. Her best-known work, Lais, is a retelling of several oral folk stories known at the time. The female characters in these lais, however, are presented as women with a clear awareness of their feminine perspective in the face of the adversities in the feudal society. Reading the Lais with a feminine (and in some cases feminist) view, we can see how the author actively criticized the model of the social order in her time and how her criticisms match the abuse of women in her century. Starting from scenes in the lais of "Guigemar", "Yonec", "Equitan" and "Milun" we will discuss how the author criticized the sexist society which she was part of. We will also 
demonstrate how her words show a tone of condemnation to a society that dictated that the woman should be entirely submissive to her male relatives and her husband. We will use the studies of Georges Duby in which he versed about women and their role in the marital society of the Middle Ages to illustrate the medieval female perspective that the author exposed, in addition to several other authors and historians who have studied the work of Marie de France with the awareness of the feminine in her writing.

Keywords: Feminism. Medieval Literature. French Literature. Marie de France.

\section{INTRODUÇÃO}

Ao discutirmos sobre as primeiras escritas femininas que se tem conhecimento no Ocidente, Maria de França é um nome que não pode ser esquecido. A autora medieval foi uma poetisa francesa que viveu durante o século XII. Seus versos em francês antigo são um dos primeiros exemplos de escritas de autoria feminina na Idade Média, principalmente na França. A autora em questão escreve com um dialeto que aparenta ter uma identidade normanda e também da Bretanha. Contudo, ainda temos grande dificuldade em criar uma bibliografia da escritora, pois sua identidade ainda permanece sendo um mistério com poucos resultados concretos. Desta forma seria mais interessante para esta análise focarmos nosso olhar para a escrita feminina da autora que buscou mostrar, em um tempo de grande exclusão das mulheres de lugares intelectuais, os primeiros vestígios de 
uma emancipação feminina. Usaremos os Lais, sua obra mais conhecida, para exemplificar como Maria de França discorreu através de identidades femininas as diversas adversidades que mulheres eram submetidas em meio à sociedade feudal. Trabalharemos nos poemas a partir do livro com tradução em português diretamente do francês antigo por Antonio Luiz Furtado e prefácio de Marina Colasanti publicado em 2001, que continua sendo a única tradução em português dos Lais no Brasil.

Através das escritas de Maria de França mostraremos como as falas das personagens e cenas dos lais burlam ordens e convenções medievais demonstrando assim, uma caracterização feminina rica e que foi escrita para representar as mulheres da época. Mostraremos como a autora expôs desigualdades na sociedade feudal nos aprofundando em como suas escritas nos mostram uma crítica feminina em tempos medievais. Utilizamos como base os conhecimentos de Georges Duby em Idade Média, Idade dos Homens (1983) acerca do papel feminino na sociedade medieval, assim como outros historiadores para entendermos mais sobre a sociedade cuja autora e suas personagens estão inseridas. As pesquisas literárias no Brasil ainda carecem de conteúdos sobre Maria de França e sua contribuição para a 
literatura feminina. No entanto, já temos diversos estudos feitos, sobretudo na área de história, que tocaram em temas relevantes para nossa pesquisa, como a dissertação de mestrado de Ligia Cristina Carvalho intitulada O Amor Cortês e os Lais de Maria de França: um olhar historiográfico (2009). Nosso foco neste estudo é demonstrar como através de sua linguagem e os temas em seus contos, Maria de França foi capaz de elucidar diferentes problemas sofridos pelas mulheres na sociedade medieval criando uma crítica, mesmo que tímida, das conturbações de seu gênero em uma sociedade inteiramente machista.

Do pouco que sabe sobre Maria de França, esta foi uma autora que viveu durante os anos 1160-1210 de acordo com Medieval France: an encyclopedia de William W. Kibler and Grover A. Zinn:

Marie's works can be dated only approximately with reference to possible patrons and literary influences. The works themselves suggest that Marie knew Wace's Brut (1155) and the Roman d'Énéas (1160), an undetermined Tristan romance, classical (notably Ovid) and Celtic sources, but not the romances of Chrétien de Troyes. The Lais are therefore dated between 1160 and 1170, the Fables between 1167 and 1189, and the Espurgatoire after 1189 and probably between 1209 and 1215, since its Latin source, the Tractatus de purgatorio sancti 
Patricii (in the version of Hugh or Henry of Saltrey), has been placed no earlier than 1208. (1995, p. 1114)

Entende-se que Maria de França estava muito bem inserida nos círculos sociais medievais da corte de Henrique II plantageneta, visto que o livro em si é um presente para o rei como dito pela própria autora em seu prefácio:

Em honra a vós, nobre rei, que tanto sois bravo e cortês, favorecido por toda alegria e em cujo coração todo bem deita raízes, dediqueime a coletar lais e a recontá-los em versos rimados. Em meu coração pensei, senhor, e disse a mim mesma que os presentearia a vós. (MARIA DE FRANÇA, 2001, p. 40)

Há teorias que a Maria seria a irmã ilegítima do rei, mas esta ainda carece de uma comprovação absoluta. Outras fontes tentam colocar sua autoria em abadessas inglesas do mesmo século, mas nada foi concretamente provado. A autora também não nos dá uma ideia muito clara de quem seja, mas seu nome acabou sendo preservado em sua pequena coleção de trabalho. Há somente algumas obras que carregam seu nome como escritora. Uma tradução das fábulas de Esopo intitulada Fábulas, um poema em francês antigo L'Espurgatoire Seint Patriz e os Lais. "Por meio das suas obras, Maria de França nos mostra ser uma mulher letrada, que conhecia o latim e era apta a fazer traduções" 
(CARVALHO, 2008, p. 5). Visto que o escopo do estudo não é a autoria da mesma, é somente necessário entendermos que Maria de França é claramente uma mulher escrevendo sobre as mulheres de sua época.

Os Lais são uma junção de doze poemas ao todo e versam principalmente sobre o amor cortês entre donzelas e cavaleiros. Os lais são intitulados respectivamente como "Guigemar"; "Equitan"; "Freixo"; "Homem-Lobo"; "Lanval"; “Dois amantes"; "Yonec"; "Rouxinol”; “Milun"; “O infortunado"; "Madressilva" e "Eliduc". A autora, em seu prefácio, mostra que já havia escutado essas narrativas: "Pensei então nos lais que ouvira. Nunca duvidei, bem sabia, que aqueles que primeiro os compuseram e divulgaram queriam através deles preservar a lembrança das aventuras que tinham ouvido" (MARIA DE FRANÇA, 2001, p. 39). Demonstrando assim que estas narrativas são reunidas de histórias orais. Acreditamos também que, sendo tradições orais, a autora pôde examinar temas específicos quando as transcreveu para o papel. Como dito por Carvalho, "[n]as culturas orais a originalidade de uma narrativa não está na elaboração de novas histórias, mas na adaptação das velhas histórias ao público presente, às novas situações" (2009, p. 25). Desta maneira, podemos ver que Maria de França se aprofundou nos temas relativos à 
feminilidade das personagens e o papel das mulheres em sua época trazendo um novo tom para os lais que já deviam ser conhecidos pelo público.

Um lai é uma palavra antiga derivada do celta laid que “[...] designa um canto semilírico e seminarrativo, em versos octossílabos, composto a fim de perpetuar a recordação de um sucesso notável, de uma aventura, cantado pelos jograis da Idade Média com acompanhamento de harpa, alaúde e flautas" (CARVALHO, 2009, p. 18). O maior tema destes contos em específico é o amor cortês da época e as relações entre homens e mulheres no que diz respeito ao amor.

Primeiramente precisamos lembrar que na sociedade medieval a mulher era sujeita ao serviço de submissão a seus familiares masculinos e logo após seu casamento era tida como um pertence de seu marido. "Todos os responsáveis pelo destino familiar, isto é, todos os homens que detêm algum direito sobre o patrimônio e, à frente deles, consideram consequentemente como seu direito principal casar os jovens e casá-los bens" (DUBY, 2011, p. 15). A perspectiva do casamento para as mulheres viria a ser o de se tornar uma estratégia para melhor inserção da família na sociedade. Logo que ela entra nesse jogo, ela deve servir seu marido e fazer o melhor para ter filhos rapidamente. 
A tomá-la alhures, numa outra casa, a introduzi-la nessa casa onde ela deixará de depender de seu pai, de seus irmãos, de seus tios, para ser submetida a seu marido, ainda que condenada a ser para sempre uma estrangeira, um pouco suspeita de traição furtiva nesse leito em que ela penetrou, onde ela vai preencher sua função primordial: dar filhos ao grupo de homens que a acolhe, que a domina e que a vigia. (DUBY, 2011, p. 15)

Há diversas críticas que a obra de Maria de França aborda, direta e indiretamente, ao universo machista que as mulheres estavam inseridas na Idade Média. Para ilustrar tais críticas, analisaremos quatro cenas diferentes em quatro lais de sua coleção. São os lais de "Guigemar", "Yonec", "Equitan" e "Milun".

Maria de França demonstra como não concorda com todas as regras impostas pela sociedade da época e passa a descrever uma perspectiva diferente em relação ao amor entre amantes. Em sua concepção, o amor será o principal motivo de todas suas histórias e a autora não vê a sexualidade e o desejo como algo que levaria à perdição. A poetisa irá, de uma forma estratégica e com algumas sutilezas elaborar algo cujos escritos masculinos não haviam se arriscado a realizar até então: dar autoridade às mulheres. 


\section{A REALIDADE DO CONSENTIMENTO NO LAI DE “GUIGEMAR"}

Como primeiro exemplo de como Maria de França usa a perspectiva feminina em sua escrita começaremos com o primeiro lai da coleção de poemas intitulado "Guigemar". Considerando que os Lais não são ainda muito conhecidos no Brasil faremos uma breve descrição da narrativa para que seus momentos mais importantes não passem despercebidos pelos leitores. Guigemar é filho de um nobre senhor e senhora e parte em uma viagem para se tornar cavaleiro. Durante uma caçada, acaba por sofrer um acidente após atirar sua flecha em uma corsa. A flecha ricocheteia da cabeça do animal e lhe fere a coxa. Ao morrer o animal diz-lhe que está fatalmente ferido e que a ferida de Guigemar não será curada até o mesmo encontrar uma mulher disposta a sentir mais dor do que ele. É notório realçar que a corsa lhe diz que deve achar uma mulher que sofra inteiramente de amor por ele, mas ao mesmo tempo, ele deve fazer o mesmo por ela. Ou seja, as dores devem ser igualadas. "Tal mulher sofrerá por teu amor tão grande pena e dor como nenhuma outra sofreu, e farás outro tanto por ela, para maravilha de todos os que amam, ou amaram, ou amarão um dia" (MARIA DE FRANÇA, 2001, p. 43).

Guigemar, ferido, adentra um navio para descansar um pouco, mas o navio começa a navegar sozinho e não tendo 
forças para escapar, o cavaleiro pede que Deus o leve para um porto seguro. A seguir, o poema nos apresenta uma senhora nobre que está em um casamento infeliz com um senhor mais velho. "O senhor que ali governava era um homem muito velho, que tinha como mulher uma dama de alta linhagem, nobre, cortês, bela e prudente. Ele era desmedidamente ciumento, como todos os velhos são por natureza [...]" (MARIA DE FRANÇA, 2001, p. 44). A donzela fica enclausurada e tem somente como companhia a sobrinha gentil de seu marido. As duas, em um momento, avistam o navio sem tripulação aparente e decidem investigar o que acontecia ali. Lá, ambas encontram Guigemar ferido que revela que a única maneira de ser curado seria pelas mãos de uma donzela. A nobre senhora passa a curar seus machucados e lhe conta como é presa por seu marido cruel, mas que cuidará do cavaleiro até que ele melhore. Com o tempo, Guigemar começa a melhorar e a se apaixonar pela dama que Ihe curou. Ele lembra então da profecia da corsa e sente-se amedrontado de revelar seu amor à donzela. Ela, do mesmo jeito, sente-se atraída por ele, mas tenta esconder seus sentimentos.

A sobrinha, percebendo que ambos estão apaixonados, decide revelar a Guigemar que sua senhora o ama e busca 
ajudar os dois amantes a ficarem juntos. O cavaleiro revela seu amor à donzela que the pede tempo para pensar no que fazer e Guigemar apela à sua senhora para que ela se dê livremente para aquele que a ama.

Dama, por Deus, piedade! Não vos enoje que vos diga: a mulher leviana de profissão faz-se rogar por longo tempo para valorizarse, e também para que não pensem que já provou desse deleite. Mas a dama de bons propósitos, que tem em si valor e senso, se ela encontra um homem a seu gosto, não se fará de orgulhosa em demasia diante dele, e sim o amará e gozará dele. (MARIA DE FRANÇA, 2001, p. 50)

Os dois amantes finalmente se juntam e seu amor é consumado durante muito tempo às escondidas. Um ano e meio se passa até os dois serem descobertos. Sabendo que logo ficariam distantes um do outro, os amantes criam uma nova promessa. A senhora faz um nó na camisa de Guigemar e lhe dá a permissão de se casar com a mulher que conseguir desatá-lo. O cavaleiro faz do mesmo jeito, um nó no cinto de sua donzela e pede que ela lhe faça a mesma promessa.

Amigo, dai-me uma garantia. Entregai-me vossa camisa; darei um nó no pano de baixo: dou-vos dispensa para amar aquela que possa desfazer o nó e desatá-lo.

Ele consentiu, fez-lhe a promessa. O nó foi feito de tal modo que nenhuma mulher o lograria desfazer se não empregasse tesoura 
ou faca. Ela devolveu a camisa. Ele a recebeu com a condição de que ela, por sua vez, lhe desse garantia, por meio de um cinto com o qual the cingiu a pele nua, apertado à altura dos flancos. Ele lhe pediu que amasse somente aquele que pudesse abrir a fivela sem despedaçá-la ou rompê-la. (MARIA DE FRANÇA, 2001, p. 51)

Guigemar é descoberto pelo marido da senhora que o bane daquelas terras no mesmo navio fantasma que ele chegou e o cavaleiro parte para buscar uma maneira de ver seu amor de novo. De volta às suas terras lhe pedem que se case logo, mas Guigemar explica que só se casará com quem desatar o nó em sua camisa. Muitas mulheres tentam, mas nenhuma consegue.

A donzela, em contrapartida, passa dois anos esperando seu amor retornar e quando este não volta, decide atirarse ao mar para morrer. Ela acaba entrando em outro navio sem tripulação (da mesma forma que Guigemar chegou naquelas terras) e acaba em outro porto na Bretanha. Ela é descoberta por Mariaduc, o senhor daquelas terras. Este a resgata e a leva para seu castelo e lhe dá tudo que a donzela pede. Ao confessar seu amor a ela, a mesma lhe diz que só se casará com aquele que desatar o nó de seu cinto já que havia feito uma promessa para seu antigo amor. Meriaduc diz que escutou falar de um cavaleiro com a mesma promessa e a 
donzela percebe que seu amado está vivo, mas começa a chorar. Meriaduc não a escuta e tenta, de maneira bruta, desatar o nó. Ele chama outros senhores para que cada um tente desamarrá-lo de algum jeito, mas ninguém consegue.

Um torneio de cavaleiros é organizado e Guigemar é chamado para lutar. Os dois amantes se reencontram, mas não se reconhecem no primeiro momento. Para tentar descobrir se estão realmente a ver seu amor, eles se põem a testar os nós nas vestes que acabam sendo desamarrados sem problema algum. Os dois explicam como se amam a Meriaduc e Guigemar se voluntaria como vassalo com centenas de cavaleiros em troca da mão da donzela. Meriaduc não aceita e diz que ela será mantida ali (já que ela é propriedade dele). Ao final do poema, Guigemar e seus cavaleiros atacam o castelo matando dezenas de pessoas e por fim, Meriaduc é derrotado. Guigemar enfim consegue resgatar sua amante. $O$ poema termina demonstrando a felicidade dos dois. "Com grande alegria libertou sua amiga: agora acabavam-se as provações!" (MARIA DE FRANÇA, 2001, p. 57).

"Guigemar" prova ser um dos lais que mais transparece a situação feminina na Idade Média. São três os pontos que achamos mais interessantes nesse poema: o primeiro 
como a independência das mulheres é sempre mostrado sem nenhum julgamento; em segundo lugar o equilíbrio no relacionamento (cada um deve viver a dor do outro) e o terceiro, e talvez o mais importante, o valor do consentimento.

Primeiramente, as mulheres que são exibidas demonstram terem vontade de serem as senhoras de seu próprio destino. Elas não possuem soberania na maioria dos assuntos, mas demonstram ter suas vontades e nunca omitem o fato de amarem alguém. Este tipo de representação estará presente em todos os poemas de Maria de França. As mulheres não se escondem de seus sentimentos, mesmo em relação aos homens. "Nos Lais, as heroínas são retratadas com especial autenticidade e, muitas vezes, sua iniciativa e inventividade, decidem o rumo das histórias" (FURTADO, 2001, p. 21-22). Guigemar recebe ofertas durante sua juventude que deveriam ser feitas durante o amor cortês e as damas nunca escondem seus flertes. "Sob o céu não haveria dama ou donzela, por mais nobre ou formosa, que não o aceitasse com agrado se ele a chamasse a amá-lo. Muitas o solicitavam muitas vezes mas ele não se importava" (MARIA DE FRANÇA, 2001, p. 42). A autora, através da fala de Guigemar, também demonstra como a mulher deve ser livre em questões amorosas para estar com aquele que ama. "Mas a dama de bons propósitos, 
que tem em si valor e senso, se ela encontra um homem a seu gosto, não se fará de orgulhosa em demasia diante dele, e sim o amará e gozará dele" (MARIA DE FRANÇA, 2001, p. 50).

A maior justificativa para Maria é a questão do amor. Ela não se opõe à ideia de amantes, justamente porque os amantes se amam independentemente de estarem casados ou não. Além do mais, diversas críticas à instituição do casamento são reveladas em seu trabalho.

O casamento - como na primeira regra de André, o Capelão - não é, para as personagens dos lais, desculpa válida para não amar, nem o adultério é motivo para qualquer sentimento de culpa. Não há limite para a fidelidade dos amantes [...] Sobretudo os lais de Maria desenvolvem-se ao redor do conceito que constitui o cerne do amor cortês: o amor verdadeiro é fonte de todo o bem, ele purifica o homem e a mulher, e os obstáculos com que se deparam só fazem exaltar sua nobreza e seu valor. (COLASANTI, 2001, p. 11)

O primeiro marido da donzela é um velho cruel que a mantém aprisionada e Meriaduc também a vê como um objeto que não deve ser retirado de suas mãos. A lei imposta pela Igreja se oporia ao fato da donzela estar enamorada com alguém fora do laço matrimonial, mas Maria mostra que se o amor for a justificativa dos amantes então a lei pode ser quebrada. "Maria de França parece 
querer demonstrar que o sentimento amoroso não leva necessariamente a prática sexual, esta pode ser uma consequência natural e não um fim irrefutável" (ANDRADE FILHO; CARVALHO, 2013, p. 478). Mesmo que o ato sexual não seja consumado, a autora demonstra como durante o ato do amor todas as doutrinas são irrelevantes. Podemos ver o quanto a autora enfatiza que para seus personagens o amor é de extrema importância. Na primeira aparição da donzela em "Guigemar" ela anda sozinha em uma capela onde é um quadro de Vênus é visto. Nele, a deusa está queimando um livro de Ovídio (um poeta que a autora já havia efetivamente lido, sendo uma estudiosa em tempos medievais). A deusa aparece como um momento de consolação para a donzela e demonstra que seu amor está prestes a chegar, contudo também pode ser um símbolo de que o amor visto pelas mulheres é levado mais a sério do que quando tido pelos homens.

$\mathrm{Na}$ Estrada erguia-se uma capela. As paredes da alcova estavam todas pintadas; Vênus, deusa do amor, figurava com destaque, mostrando a natureza do amor e as regras de como se deve amar e bem e lealmente servir. Lançava ao fogo ardente o livro de Ovídio, em que ele ensina como reprimir o amor, e excomungava todos os que jamais lessem esse livro ou praticassem seus ensinamentos. (MARIA DE FRANÇA, 2001, p. 45) 
Susanne Klerks em "The Pain of Reading Female Bodies in Marie de France's 'Guigemar'” discorre sobre a importância da leitura da figura de Vênus na cena "When Venus burns what is presumably the Remedia Amoris, she displaces the male authority of Ovid and presents herself as an alternative, female authority on love" (1995, p. 3, grifo do autor). Ao explicitamente queimar o livro de Ovídio, a poetisa coloca a mulher como a autoridade em questões amorosas já que ela é a que melhor sabe exemplificar as questões do coração.

De certo, a escrita pode não ser totalmente feminista, mas é inteiramente feminina. Ainda há resquícios de uma misoginia que será permeada durante muito tempo, mas a poeta nos mostra como ela irá tentar burlar essa sociedade. Afinal, a donzela principal não tem um nome, diferente da maioria dos personagens masculinos da narrativa. Ela, porém, tem uma voz, desejos e escolhas que devem ser levadas em conta ao estudarmos suas características na narrativa.

Da mesma forma, ao mencionar as personagens femininas da história, também devemos levar em conta a sobrinha da donzela e como esta age como confidente e amiga, assim ajudando sua senhora a encontrar o verdadeiro amor. Ela sabe da maldade de seu tio e como sua senhora é confinada a uma vida de sofrimento e solidão criada pelo laço matrimonial. 
É a sobrinha que faz com que os dois amantes juntemse revelando um ao outro como se amavam. "A rapariga confortou o cavaleiro com grande doçura, e garantiu-lhe ajuda em tudo que pudesse favorecê-lo; era muito cortês e amável" (MARIA DE FRANÇA, 2001, p. 49).

Outro ponto interessante da narrativa é a igualdade entre os dois amantes. Ao morrer, a corsa diz a Guigemar que ele deve encontrar uma mulher disposta a sentir uma dor enorme por ele e ele deve sentir o mesmo por ela. Os dois sofrem juntos desde o início do poema. A dor da donzela, porém, é sempre maior do que a de Guigemar (outra perspectiva feminina que a autora nos mostra). Guigemar está ferido pela corsa e é curado pela mulher maltratada pelo orgulho de seu marido. Logo após, os dois sentem novas dores por se amarem e não saberem se o amor é correspondido. Quando Guigemar é banido, este pode retornar a sua casa e viver com sua família enquanto melhora suas habilidades de cavaleiro. A senhora, em contrapartida, deve viver ainda mais dois anos na casa de seu marido cruel, tanto que sua única escapatória é o suicídio. Será que a autora estava querendo indicar que as mulheres sempre sofreriam mais do que os homens (mesmo em questões de amor)? É pertinente pensar que sim. Esta seria mais uma artimanha da autora para nos revelar as dores 
que seu sexo vivia em sua época e se apresenta também nos outros poemas de sua coleção como mostraremos nas próximas seções.

Agora devemos nos ater para o que talvez seja o maior tema deste poema: o consentimento. Esta questão é revelada através da cena dos nós. Antes de se separarem os amantes decidem amarrar nós um na roupa do outro (ela na camisa dele e ele no cinto dela). Se alguém conseguisse desatar este nó então esta pessoa teria a permissão para se casar com um dos dois. Contudo, ninguém, além dos amantes, obtém sucesso nesta missão. Achamos importante também demonstrar como as cenas onde se é tentado desamarrar o nó é diferente para o homem quanto para a mulher.

Quando as mulheres tentam desamarrar o nó de Guigemar, a cena é tida como um jogo no qual as donzelas interessadas terão Guigemar como prêmio: "Pela Bretanha correram as novas; não havia dama ou donzela que não fosse tentar: nenhuma conseguiu desatá-la" (MARIA DE FRANÇA, 2001, p. 52). É interessante notar, no entanto, que não é percebido nenhum tipo de violência sendo mencionado mesmo quando o cavaleiro está sozinho nas mãos de dezenas de mulheres.

Guigemar is under no threat from the hordes of women who wish to untie his knot, because the physical dynamics involved in 
the women's attempt to undo his knotted shirt do not make him vulnerable: he is not exposed in any way during this process, nor is any weapon mentioned. (KLERKS, 1995, p. 8)

A donzela, porém, recebe um tratamento mais violento quando tentam desatar seu nó, visto que os homens não se preocupam com suas lágrimas ou com seus sentimentos no momento. "Ele a colheu nos braços, cortou-Ihe os laços da túnica; queria abrir o cinto, mas não conseguiu. Desde então não houve no país cavaleiro que não viesse tentar" (MARIA DE FRANÇA, 2001, p. 54). É importante notar que sua túnica é rompida, dando claros indícios para uma narrativa de estupro da senhora na presença de Meriaduc e seus vassalos. A dinâmica entre aquele que desata o nó e a donzela serve para exemplificar como as relações são diferentes quando o homem tem o poder sobre o corpo da mulher: "[...] the heroine's encounter with Meriaduc is tinged with violence. Meriaduc, in fact, stands as an emblem of courtly aggression: his antifemale violence is connected to his position as a feudal lord" (KLERKS, 1995, p. 8-9).

Como dito por Furtado, a cena dos nós pode ser vista como uma das funções de Vladimir Propp, em que o herói tem algo em si marcado e destacado para ser reconhecido depois: "O aparente absurdo da cena fica patente na 
curiosa racionalização de Guigemar, tentando justificar sua perplexidade: 'as mulheres às vezes são tão parecidas umas com as outras!'” (2001, p. 25). No caso deste lai tanto o herói quanto a heroína têm algo destacado em seu corpo para ser descoberto depois. Contudo, do modo que Maria de França descreve suas cenas e com as diversas críticas à cultura da época vemos que a cena dos nós tem mais a ver com o valor do consentimento. Somente quando um consente em se entregar para o outro é que o nó será desfeito. Guigemar não consente para as mulheres e por isso elas não desamarram sua camisa. A donzela também não consente para Meriaduc ou seus cavaleiros, por isso ninguém terá sucesso em desatar seu nó. "Marie de France, as a woman in a culture desensitized to antifemale violence, rewrites women's position in courtly discorse. Rather than valorizing this violence, she reveals women's marginalized positions within courtly literature" (KLERKS, 1995, p. 8). É, contudo, muito aparente a desigualdade de dinâmicas entre feminino e masculino quando simbolizamos os nós como o consentimento destes personagens. Para o personagem masculino, o desatar de sua camisa é tido como um jogo enquanto para a personagem feminina a violência em seu corpo é explícita. 


\section{DEMONSTRANDO INDIGNAÇÃO NO LAI DE “YONEC"}

Para a próxima investigação, trabalharemos com o sétimo lai da coleção "Yonec". Este é um lai que compartilha de temas em comum com "Guigemar" por também apresentar um amor escondido e uma donzela que é confinada em seu casamento por seu marido cruel. Diferente de "Guigemar", no entanto, a donzela não é ajudada por sua sobrinha e sim sofre nas mãos da irmã de seu senhor que a mantém cativa dentro de seu quarto e que não permite que ninguém the veja. A donzela pede aos céus por uma condição de vida melhor (na cena que iremos observar) e um pequeno açor entra em seu quarto transformando-se em um cavaleiro. Os dois amantes compartilham de grande felicidade até que são descobertos pela irmã do marido e o açor é ferido fatalmente. A donzela, no entanto, revela que está grávida de seu amigo e o cavaleiro pede que ela batize o filho de Yonec para que este possa vingar o pai no futuro. A criança cresce e finalmente a verdade sobre quem fora seu pai é revelada. Sua mãe cai morta após contar o segredo e o filho mata o senhor que aprisionava sua mãe no casamento e que anteriormente havia matado seu pai, o cavaleiro pássaro.

O lai foca primeiramente na tristeza da donzela para depois focar no amor dos amantes e por fim na vingança 
do filho. Ele contém diversos temas que também são encontrados nas outras narrativas da coleção de poemas.

A figura do pássaro é tida em pelo menos três narrativas em que se estabelece a ligação entre os amantes. Em "Rouxinol" para despistar seu marido dos encontros com seu amante, uma donzela diz que fica acordada de noite para escutar o canto de um rouxinol. O marido desta mata o pássaro para que ela não precise ficar acordada novamente e seu amante passa a usar o pássaro morto em volta do pescoço como símbolo de seu amor perdido. Em "Milun" (outra narrativa na qual os amantes devem se encontrar às escondidas pelo fato da dama já estar casada), um cisne é a forma de comunicação entre o casal que vive a enviar cartas às escondidas um ao outro.

Vários dos temas narrativos das histórias vêm do folclore da época. Já mencionamos aqui sobre a marcação de Propp e esta aparece em diversos outros lais da mesma forma. Em "Freixo" uma criança é adornada com algumas joias para que se reconheça que esta é de uma família nobre e ao final do lai estas joias são o que a fazem retornar para a família. "Madressilva" é uma interpretação de uma parte da história de Tristão e Isolda que consequentemente também escondem seu amor dos vínculos do casamento já que Isolda 
é casada com o rei e não o ama. Outra marcação é mostrada quando Tristão escreve seu nome em um galho de aveleira a espera que seu amor o note.

A fonte básica declarada consistiria em lais anônimos divulgados oralmente, com todas as características comuns ao folclore. Numa decisão feliz que contribuiu para manter a atmosfera feérica dos lais primitivos, Maria não quis expurgar certos elementos irracionais, bem conhecidos pelos estudiosos de folclore. (FURTADO, 2001, p. 25)

Entretanto, o que podemos observar neste estudo é como outro elemento que se repete através das narrativas são as demonstrações de perspectiva e consciência feminina para diferentes personagens que compartilham o mesmo destino: o de terem nascido como mulheres. Para a autora, não é importante se a mulher vem de berço nobre ou simples. As experiências se mantêm as mesmas em relação ao abuso matrimonial e a busca pelo amor verdadeiro.

Em "Guigemar" e "Yonec", mesmo sendo de famílias nobres, as donzelas são confinadas por seus maridos mais velhos e ciumentos. Temos diversos exemplos em outros lais: Após ser acusada de infidelidade, uma esposa é mantida confinada em casa em "Freixo" exemplificando mais uma vez a prisão do casamento. Em "Dois Amantes", no entanto, é um pai que confina a filha para evitar que a mesma se 
case. Lembrando-se das palavras de Georges Duby "[...] ela deixará de depender de seu pai, de seus irmãos, de seus tios, para ser submetida a seu marido[...]" (2011, p. 15). A noção da sociedade medieval ditava que as mulheres sempre pertenceriam aos homens, e por consequência, precisamos que as falas das personagens femininas nas narrativas sejam levadas com grande consideração. Maria de França não está somente exibindo a desigualdade que as mulheres sentiam na época, ela está claramente criticando-a de maneira poética.

The imprisoned wife, the lady in a tower, is a leitmotif of the Lais that cannot be separated from the marital practices of France's nobility at the end of the first feudal age, or from the conflict between lay aristocratic and ecclesiastical models of marriage, [...]. (BLOCH, 2003, p. 59)

Por exemplo, uma das primeiras falas da personagem no lai de "Yonec" demonstra sua indignação com a situação em seu casamento. Entristecida com sua condição de cativa, não podendo nunca sair para passear e tendo que pedir permissão para sua cunhada (única pessoa fora do marido que tem a permissão de vê-la) a personagem faz um lamento que descreve a situação social em que se encontra:

Infeliz, em má hora nasci! É muito duro meu destino. Estou aprisionada nesta torre, 
não saírem dela senão por morte. Este velho ciumento, de que tem medo que me mantém em tão forte prisão? É muito louco e atoleimado. Teme sempre ser traído. Não posso ir à igreja nem assistir ao serviço divino. Se pudesse conversar com as pessoas e sair a passeio com ele, mostrar-lhe-ia cara alegre, mesmo contra minha vontade. Malditos sejam meus parentes e todos aqueles que me deram a este ciumento $e$ me fizeram casar com ele. [...] Muitas vezes ouvi contar que se costumava achar outrora neste país aventuras que devolviam a alegria aos aflitos. Os cavaleiros encontravam jovens a seu gosto, nobres e belas, e as damas encontravam amantes belos e corteses, honrados e valentes, e não eram censuradas por causa deles nem ninguém, afora elas, os viam. Se isso pode ser, se deveras já foi assim, se alguma vez aconteceu com alguém, praza a Deus, que tem poder sobre tudo, fazer-me a vontade! (MARIA DE FRANÇA, 2001, p. 101102, grifo nosso)

A donzela se encontrava em uma condição infeliz cuja perspectiva era o sentimento em comum das mulheres da época. Esta se põe a amaldiçoar seus parentes e aqueles que lhe colocaram nesta prisão. Afinal, o casamento como já demonstramos, não era visto pela autora como um lugar de florescimento de amor - especialmente vindo do fato de que as mulheres deveriam ser entregues aos maridos e a partir disso, virar seus objetos. "Com efeito, o homem que toma mulher, qualquer que seja sua idade, deve-se comportar-se como senior 
[mais velho, senhor] e manter essa mulher sob rédeas, sob seu estrito controle" (DUBY, 2011, p. 33, grifo do autor).

A necessidade do casamento vinha da criação de um processo social no qual a mulher teria o dever de produzir os herdeiros daquela terra. Assim sendo, esta era sua função primordial e essencialmente, sua única função, já que se a mulher fosse infértil ou quando não pudesse mais ter filhos era tratada como inútil pela sociedade. A questão da escolha do marido ou da condição que iria viver não dependia da mulher e de seus desejos e sim da estratégia que a sociedade patriarcal alocaria para melhor preencher os espaços da ordem social.

Pelo fato de que a ordem social repousa inteiramente sobre o casamento, do casamento ser uma instituição, um sistema jurídico que liga, aliena, obriga enfim a que seja assegurada a reprodução da sociedade nas suas estruturas, especialmente na estabilidade dos poderes e das fortunas, não the convém acolher a frivolidade, a paixão, a fantasia, o prazer; e quando ele começa a acolhê-los, não é porque essa instituição já perdeu suas funções e tende a desagregar-se? O casamento impõe o sério, a compostura. (DUBY, 2011, p. 42)

É por isso que em suas narrativas as donzelas não são reprimidas por terem vínculos fora do casamento. A instituição do matrimônio, como acusado por Maria, só 
servia para o controle de corpos femininos e para melhoria de títulos entre os homens. Suas personagens são leais e justas, mas com aqueles que elas mesmas escolhem, este seria o verdadeiro vínculo a ser respeitado. "Já a fidelidade é representada na relação da jovem com seu amante, pois essa união é a única válida, já que é fruto da livre escolha" (SILVEIRA, 2014, p. 65).

\section{CONDIÇÃO FEMININA NOS LAIS DE "EQUITAN" E “MILUN"}

Todavia as mulheres não são sempre demonstradas com carinho e delicadeza. Maria de França foi justa em mostrar outras perspectivas femininas e personagens diferentes da donzela que necessita de ajuda. São os casos dos lais "Equitan", "Freixo" "Homem-Lobo" e "Lanval". Nesses casos, nem todas as personagens são caracterizadas pelo amor cortês e suas forças em frente às provações de sua sociedade. Elas continuam tendo força de vontade de criar seus próprios destinos, mas abordam maneiras mais violentas de conquistálos. No caso de "Equitan" e "Homem-Lobo" são narradas as tentativas de esposas que tentam deixar seus casamentos em função de um amante novo, algo bem pertinente aos lais, contudo, nessas narrativas as personagens são apresentadas como perversas e cruéis. Armam artimanhas para terem seus caprichos atendidos e, em certos momentos, não 
hesitam em planejar assassinatos. Nesses lais a narrativa se apresenta de uma forma mais moralista para mostrar os perigos de atitudes cruéis, e de certa forma, para dar um tom mais "cristão" ao texto. Nem sempre podemos justificar as ações maldosas das personagens femininas, embora possamos entender o porquê estas foram feitas. "[...] é possível afirmar que as personagens de Maria de França têm vontades próprias e trabalham com os recursos que têm e com a inteligência para flexibilizar os limites que a sociedade Ihes apresenta" (CEREJO, 2017, p. 91).

No caso de "Lanval" a rainha consorte de Rei Arthur encurrala um cavaleiro para que este se torne seu amante. Quando é recusada (já que o cavaleiro amava outra donzela) a rainha se põe a criar mentiras para o rei com o intuito de fazer com que o cavaleiro seja executado. Um tribunal é tido em meio à corte e a donzela amante do cavaleiro o defende provando sua inocência diante das mentiras da rainha.

Em "Homem-Lobo" ao descobrir que seu marido vira lobisomem em certos dias do mês, uma mulher, enojada por saber desta condição, arma um esquema com seu amante para que seu marido nunca vire homem novamente. Ao ser transformado e não poder voltar a sua forma natural, o homem acaba se tornando o animal de estimação de um 
senhor nobre. Quando a esposa e seu amante (que agora havia se tornado seu marido) chegam à corte deste senhor, o animal os ataca violentamente, revelando que os dois haviam cometido um crime.

Para Jaqueline Eccles em "Feminist criticism and the lay of "Lanval'": A Reply" o motivo da autora narrar personagens femininas manipuladoras nos mostraria como Maria de França não quis somente demonstrar que os homens eram os responsáveis pelo sofrimento das mulheres, mas como as características femininas também poderiam vir a ser cruéis, enriquecendo assim as personagens.

In Lanval, the chief manipulator of Arthur's court is a woman. In this respect Guinevere is a cautionary symbol, portraying female weakness and cunning. This balances the weakness and fallibility we have already seen in the male characters and provides us with a more rounded view of the feudal court society. This nullifies the argument that Marie's text might be sexist in favor of the female. (1998, p. 284)

Andrade Filho e Carvalho elaboram que a necessidade de se criar personagens manipuladoras femininas nesses lais nos revela o fato de que Maria estava escrevendo para uma audiência masculina e assim deveria colocar personagens que eram pertinentes com a visão machista sobre as mulheres: 
A narrativa, para alcançar sucesso, deve agradar os ouvintes, dentre os quais estão os homens. Assim, para agradá-los era preciso corresponder ao sentimento de apreensão diante da mulher que julgavam perigosa, fato que comprova a penetração na cultura aristocrática da concepção clerical da mulher. (2013, p. 487)

De fato, a autora estava apresentando uma perspectiva misógina para sua audiência em certos lais, mas, da mesma forma, estava elaborando sua crítica em meio à misoginia e enaltecendo a riqueza de suas personagens com suas palavras.

O lai que analisaremos a seguir é "Equitan". Um rei nobre se apaixona pela esposa de seu senescal e lhe pede para tê-la como amante. A mulher lhe diz que sente muita ansiedade em virar sua amante visto que caso o rei queira a desprezar, esta ficaria desamparada. Ela diz que preferiria que seu marido estivesse morto para poder se casar com o rei. Os amantes armam um esquema no qual após o rei e o senescal saírem para caçar e voltarem para um banho, a banheira do senescal estaria armada com água fervente onde ele cairia e sua morte seria dada como acidente. Contudo, o senescal acaba encontrando os amantes antes de seu banho. No desfecho, em meio a toda a confusão, o rei cai por acidente na banheira de água ardente. A mulher, em contrapartida, é atirada ao mesmo banho pelo marido traído sendo assim 
assassinada. O lai termina com um tom moralista: "Saiba quem busca o mal de alguém, / que é contra ele que o mal vem" (MARIA DE FRANÇA, 2001, p. 64).

Contudo, mesmo que "Equitan" seja um lai de cunho moral e que demonstra como as narrativas também eram usadas como modo de educação, uma das falas da personagem feminina nos revela outro exemplo de como as mulheres se sentiam na situação que se encontravam em sua sociedade, desta vez em relação à igualdade:

Senhor, quanto a isso necessito de trégua para pensar; desta feita, não me sinto segura. Sois reis de grande nobreza - não é tanta minha riqueza que vos convenha tomar-me como amiga nem amar-me. Tendo feito em mim vossa vontade, sei deveras, não duvido nada, logo ireis me abandonar, deixando-me muito pior do que antes. Se fosse o caso de eu vir a amarvos, e assim acedesse a vosso pedido, os papéis nesse jogo não seriam repartidos igualmente entre nós dois. Isso porque sois rei poderoso enquanto meu marido é vosso vassalo; cuidaríeis, segundo imagino, de simplesmente estar exercendo vosso direito de senhor. Não é fidalgo o amor se não é igual. Mais vale um pobre homem leal que tenha em si sendo e valor, e seu amor produz mais alegria, do que o de príncipe ou rei, quando Ihe falta lealdade. Se alguém ama acima do nível que convém a sua fortuna, vive inseguro de todas as coisas. 0 homem rico tem de tomar precauções, por 
seu lado, para que ninguém lhe tire a amiga com quem pretende fazer amor por força de seus privilégios. (MARIA DE FRANÇA, 2001, p. 60)

A fala da personagem prova ser, não só uma crítica ao sistema feudal e sua diferença entre classes como também a noção que a senhora tem que caso os dois fossem descobertos ela sofreria mais do que o amante, este sendo rei e homem e ela de classe menor e mulher. $\mathrm{O}$ fato realmente se concretiza, afinal, o rei morre acidentalmente no banho enquanto a mulher é assassinada pelo marido.

A questão da violência contra as mulheres, como foi mostrado na questão dos nós em "Guigemar" aparecenos em outros poemas. Quer a mulher seja vista de forma favorável ou não, em meio às narrativas a mulher sempre sofre mais que o homem. Em "Homem-Lobo", o lai do lobisomem, quando o animal morde os dois amantes, o marido é ferido um pouco enquanto o nariz da mulher é arrancado completamente. Caso isto não bastasse, a mulher neste lai é também torturada para que se descubra o porquê o animal a detesta tanto.

A verdade é que para Maria de França as mulheres deveriam ser livres para escolherem seus amantes e suas vidas. Em outras narrativas seria comum ver que 
ao cometessem adultério ou explorassem a mais sua sexualidade as mulheres seriam punidas de modo a educar qual o espaço que a mulher deveria ficar. Maria pune algumas de suas personagens, mas a punição não vem pelo fato de serem mulheres. Ela pune suas personagens por mentiras e assassinatos, mas nunca por sua condição feminina. Ela, porém, nos mostra como as mulheres viriam a ser castigadas na época pela mesma sociedade patriarcal ao serem submetidas às vontades dos homens.

Na verdade, não faltam alusões às jovens insubmissas. Mas tais reivindicações de liberdade são denunciadas como censuráveis no momento em que a jovem recusa aceitar aquele que foi escolhido para ela, em que afirma amar um outro, no momento em que ela fala precisamente de amor - e logo o Céu a castiga. Ou então essas resistências são objeto de louvor quando se trata de um outro amor, o amor a Deus, quando as núpcias são repelidas por um desejo de castidade. (DUBY, 2011, p. 35)

Analisaremos a seguir mais uma cena dos lais que nos mostra a consciência feminina na sociedade medieval. Em "Milun", temos outra narrativa que perpetua o desejo fora do casamento. Milun é um cavaleiro que ama sua amiga fielmente. Os dois amantes têm diversos encontros felizes até que a mulher engravida. Milun pede que a criança 
seja levada para sua irmã quando nascesse para que esta pudesse cuidar de seu filho até que a criança estivesse na idade de saber quem é seu pai. Milun parte da terra e sua amiga é dada em casamento para outro homem. Sabendo da realidade feminina ao não ser mais virgem, a personagem nos revela que sabe qual direção sua vida irá tomar agora que ela não tem mais sua virgindade como defesa.

Milun partiu de sua terra, como mercenário, para conquistar fama. Sua amiga ficou em casa. O pai prometeu-a como esposa a um barão do país, homem muito rico, muito esforçado e de grande valor. Quando ela soube o que a esperava ficou na mais profunda tristeza e repetidamente queixouse de Milun, pois muito temia ser desprezada por ter tido filho, como o esposo descobriria de pronto.

- Infeliz, que farei? Terei marido? Como o acolherei? Já não sou nenhuma virgem; serei tratada como serva pelo resto da vida. [...] Mais me vale morrer do que seguir vivendo. (MARIA DE FRANÇA, 2001, p. 117, grifo nosso)

Do mesmo jeito que a donzela em "Equitan" sabia de sua condição como mulher de seu espaço social, a dama de "Milun" também nos expõe sua perspectiva feminina em relação à sociedade machista e patriarcal que reprime as mulheres. É comum nos lais vermos as personagens preferirem o suicídio a continuarem em suas respectivas 
condições demonstrando que, em certos casos, a morte seria preferível a viver como mulher.

Em "Milun" a esperança de rever seu amor verdadeiro é concedida à personagem no final da narrativa. Os dois amantes continuam a trocar correspondências durante todos os anos através de um cisne e no final do poema podem ficar juntos novamente quando o marido da dama é morto e o filho é reencontrado pelos pais.

É interessante perceber que Maria deu alguns finais felizes para algumas de suas personagens e para outras não. Sendo de boa índole ou não, as personagens são retratos bem feitos da cultura e condição da mulher na Idade Média, que poderiam ser dóceis e gentis, mas que também eram capazes de provocar tanta dor quanto os homens. As críticas elaboradas no trabalho de Maria são pertinentes ao estudo de literatura feminista, mas seu trabalho não pode ser reduzido somente a sua crítica, já que é também uma rica narrativa de personagens femininas.

[...] Marie reveals herself to be a true woman in many of the most interesting passages of the Lais. In her use of forceful, pictureste, and superlative expressions: in her use of exaggeration and diminutives and detail of description, she speaks the language of woman of all times. In her detailed description of cloth, clothing, furniture, 
architecture, adornment, and people, she shows where her womanly interests lie. She reveals other feminine characteristics in her interest in domestic affairs, in children and their care, in her knowledge of the most efficacious use of women's charms and the effects of those charms on men, and in her lack of interest in martial events. Finally, in the vengeances employed, she reveals herself as a woman who appreciated and could use the ultimate in ruthless and coldhearted poetic justice, and as possessing a cruel subtlety which few, if any, men could equal. (WOODS, 1950, p. 19)

\section{CONCLUSÃO}

Desta forma, qual seria o valor da crítica feminina ou feminista de Maria de França? "Women become feminists by becoming conscious of, and criticizing the power of symbols and the ideology of culture." (HUMM apud ECCLES, 1998, p. 282) Através do uso de símbolos de sua cultura, a autora utilizou seu conhecimento da época e sua consciência como mulher para elaborar críticas condizentes com sua perspectiva feminina. Não é somente a crítica contra a sociedade feudal sendo estabelecida em suas escritas, mas possivelmente os primeiros traços de uma crítica feminista francesa. Eccles, no entanto, não concorda com a ideia de chamar Maria de feminista:

Although obviously troubles by the feudal society in which she lived, there is no hint of malice or unjust criticism in her writing. 
To say that Marie wrote as a woman, or indeed as a feminist, would be to belittle her talent. Her work lends itself well to feminist criticism and to see it applied is challenging. (1998, p. 285)

Seria, de fato, desconcertante se a escrita de Maria fosse reduzida somente a essa crítica, sendo que a autora demonstra ter um conhecimento vasto de literatura e uma visão artística notória. Mas Maria de França escreve como uma mulher e coloca sem dúvidas os problemas que seu sexo vivenciava nessa sociedade. Acreditamos que ela não está somente ilustrando a vida cotidiana real na Idade Média, pois suas palavras nos mostram um tom de grande indignação com a situação feminina em meio ao patriarcado.

Os escritos literários podem não ser um retrato fiel da sociedade da qual eles partem e da qual eles se referem, entretanto, esses escritos, assim como outras fontes medievais, têm o mérito de demonstrar a sociedade a seu modo, fornecendo, muitas vezes, uma imagem realista da mesma. (CARVALHO, 2009, p. 12)

Escrevendo como uma mulher na França medieval teria seus obstáculos. A autora não se diminuiu frente a eles, mas buscou domá-los para que sua visão fosse tida como respeitável. Nas primeiras linhas de "Guigemar", que é o início da coleção de poemas, Maria de França já prevê que será alvo 
de zombaria (ou talvez esta fosse uma condição cuja autora já tivesse experiência, dado que os Lais aparentemente não foram sua estreia na escrita). Contudo, a autora defende seu espaço e sabe que continuará seu trabalho.

Mas, em qualquer país em que haja homem ou mulher de grande valor, é comum que os que invejam sua sorte espalhem vilanias: querem aviltar seu mérito; e assim comportam-se como o perverso cão covarde, traiçoeiro, que morde as pessoas por maldade. Nem por isso vou desistir: se por força de zombaria ou de lisonja querem queixar-me mal, é direito deles a maledicência. (MARIA DE FRANÇA, 2001, p. 41)

As cenas dos lais que foram analisadas aqui são as que mais achamos pertinentes ao demonstrarmos as críticas femininas da autora em meio à sociedade patriarcal. Mas não são as únicas. O trabalho de Maria de França está repleto da voz e consciência feminina que se apresenta como insubmissa na frente de uma cultura que a desvaloriza constantemente. Maria declama sobre consentimento, amor verdadeiro, indignação, violência contra a mulher e igualdade provando seu valor como mulher e como integrante da sociedade. Seu trabalho não pode ser reduzido em nenhum dos casos. Ela deve ser estudada como artista, mas é necessário, também, levar em consideração suas críticas feitas à ordem social medieval. 
A escritora nos expõe ainda uma visão do feminino dotada de dinamismo e raciocínio, ao mesmo tempo que deixa ver limitações que faziam parte do cotidiano cortesão e que obtinham suporte em uma sociedade cujo poder estava predominantemente na mão de homens que não compreendiam o feminino e, em decorrência disso, o temiam e desprezavam. (CEREJO, 2017, p. 91)

Maria sabia do poder que sua escrita teria para provocar mudanças na sociedade. Ao apresentar os lais para o rei, a autora talvez tivesse esperança que quanto maior o público de sua escrita, maior a chance que estes problemas poderiam evocar empatia para assim serem evoluídos. "Marie may not have been what contemporary critics call a feminist, but her challenge to the social make-up of her society certainly proves that she was more than conscious of her power to effect change through her writing" (ECCLES, 1998, p. 282).

A passagem da oralidade destas narrativas para a escrita já é de extrema importância para que as mesmas não fossem perdidas. Infelizmente nunca se saberá como os lais originais eram contados na época e quais foram as modificações que a autora executou, contudo acreditamos que a inserção da voz feminina e das atitudes das personagens como mulheres é uma grande pista que nos mostra que Maria de França transcreveu os lais sempre tendo em vista as desigualdades 
que as donzelas sofriam. Talvez as donzelas de "Yonec" e "Guigemar" não se queixassem de suas vidas confinadas em seus casamentos na versão original de seus contos. Talvez a dama de "Equitan" não versasse eloquentemente sobre igualdade em um relacionamento com um rei quando os lais eram cantados pelos jograis nos salões. Talvez a dama de "Milun" simplesmente aceitasse seu destino como serva dos homens quando Maria de França escutou sua história em sua infância. Ao dar autoridade para suas personagens, Maria trouxe a perspectiva e consciência feminina coletiva para o topo da história.

A intenção de Maria, ela mesma esclarece: para que essas histórias que ouvia não se perdessem no tempo. De fato, em sua empatia às histórias de protagonistas femininas é expressa a necessidade de falar desse mundo, calado nos romances de cavalaria e na realidade da cristandade latina medieval. Seria um movimento de resistência feminina diante de uma sociedade que tolhe seu direito de escolha? Sim, uma estratégia de construção de memória de uma época idílica, na qual o consorte deveria ser escolhido pela mulher. (SILVEIRA, 2014, p. 73)

Seu trabalho é uma miríade de símbolos e cenas femininas, assim como críticas à sociedade que as põem para baixo. Uma luta contra o patriarcado e o feudalismo no qual ela e todas as mulheres estavam inseridas. Assim sendo, o trabalho de 
Maria de França não pode ser estudado simplesmente como uma coleção de transcrições de poemas orais para escritos. Ele também é uma amálgama de protestos contra uma sociedade misógina medieval.

\section{REFERÊNCIAS}

ANDRADE FILHO, Ruy de Oliveira; CARVALHO, Lígia Cristina. A misoginia medieval e seus ecos nos Lais de Maria de França. Mirabilia, v. 17, n. 2, p. 467-494, 2013. Disponível em: https://ddd.uab.cat/pub/mirabilia/ mirabilia a2013m7-12n17/mirabilia a2013m7-12n17p467.pdf. Acesso em:1 de fev. de 2021.

BLOCH, R. Howard. The anonymous Marie de France. Chicago: The University of Chicago Press, 2003.

CARVALHO, Lígia Cristina. O Amor Cortês e os Lais de Mais de França: um olhar historiográfico. 2009. 186f. Dissertação (Mestrado em História) - Faculdade de Ciências e Letras de Assis - Universidade Estadual Paulista, 2009. Disponível em: https://acervodigital.unesp.br/ handle/11449/93390. Acesso em: 1 de fev. de 2021.

CARVALHO, Ligia Cristina. O problema da autoria nos lais de "Maria de França". Reuni-Revista Unijales. 3. ed., n. 3, 2008. Disponível em: https://reuni.unijales.edu.br/edicoes/7/o-problema-da-autoria-nos-laisde-maria-de-franca.pdf. Acesso em: 1 de fev. de 2021.

CEREJO, Júlia Zaniboni. Lai dos Dois Amantes: da oralidade Bretã às letras corteses de Maria de França. Anais do III Encontro do Grupo de Trabalho em História Antiga e Medieval - ANPUH - SC. Florianópolis, p. 84-92, 2017.

DUBY, Georges. Idade Média: Idade dos Homens. Tradução de Jônatas Batista Neto. São Paulo: Companhia das Letras, 2011.

ECCLES, Jacqueline. Feminist Criticism and the lay of "Lanval": A reply. Romance Notes. University of North Carolina at Chapel Hill, v. 38, n. 3, p. 281-285, 1998. 
KIBLER, William W.; ZINN, Grover A. Medieval France: an encyclopedia. Psychology Press, 1995.

KLERKS, Suzanne. The Pain of Reading Female Bodies in Marie de France's "Guigemar". Dalhousie French Studies. Dalhouse University, v. 33, p. 1-14, 1995.

MARIA DE FRANÇA. Lais. Introdução e tradução de Antonio L. Furtado. Prefácio de Marina Colasanti. São Paulo: Editora Vozes, 2001.

SILVEIRA, Aline Dias. A morte e a iniciação feminina nos lais de Maria de França. Revista Brasileira de História das Religiões - ANPUH. v. 6, n. 18, p. 59-74, 2014.

WOODS, William S. Femininity in the "Lais" of Marie de France. Studies in Philology. University of North Carolina Press, v. 47, n. 1, p. 1-19, 1950.

Gabriela Carlos Luz

Mestra (Universidade Estadual Paulista - UNESP).

Participa do grupo de pesquisa "Vertentes do Fantástico na Literatura" (CNPq/UNESP).

http://lattes.cnpq.br/6084431522486845

https://orcid.org/0000-0001-8951-6246

gabrielacarlosluz@gmail.com 